\author{
Michael Moore \\ William Jeffrey Welsh \\ Bowling Green University
}

History Departments in many schools have been beset not only by declining enrollments and cost-conscious administrators, but they have also had to consider pedagogical and curricular problems as well. Most of them are hardly new but, as the cycle of undergraduate curriculum reform seems, to some, to be returning to a more traditional format, they do raise important questions. Two such questions are the focus of this essay: Is history's role vis-a-vis current curricular changes different from what it had been; and how can a college instructor implement those changes in the classroom?

\title{
HISTORY AND CURRICULAR CHANGE
}

In 1976, the History Department at Bowling Green State University, Ohio, offered a freshman-level course entitled The Study of History (or History 101), whose goal was to:

- . [stress] concepts and skills rather than chronology; why history is important as a way of thinking and how historians' explanation of human behavior through change and time links perspectives and findings of other fields of study.

Equally ambitious was the department's intent that History 101 be a "cornerstone of a student's general education, that regardless of major a student would learn skills and concepts central to whatever field of endeavor he or she would undertake." Thus, two major promises were made: to teach history as a way of thinking worth studying for its own sake, and to restore history to a preeminent position in the undergraduate general education curriculum.

The first promise opened a debate within the department over the role and function not only of the 101 course, but of the entire 100 and 200 series of courses. Were all of these ostensibly introductory courses too narrowly geared toward the history major? Did the constraints under which the traditional introductory courses labored stress content-acquisition at the expense of other skills? If, however, a course stressing skills at the freshman level was to be offered, could it, in the words of a colleague, offer anything "substantive"? What would be the difference between such a course and a graduate seminar on historiography or historical research methods? And finally, would a skills course compromise history's traditional claim to inclusion in a general education curriculum, that it taught a unique and broad kind of synthesis?

In an attempt to cope with these questions and to get a clearer picture of what the 101 course would do, we drew up three models that appeared to describe most of the teaching approaches in use:

a. Descriptive History is associated with the "names-dates-places" style of teaching. The content is "fact," the style didactic, the text heavy, and the skill rote memorization. To most people this may be what they perceive as historical synthesis primarily because they have not been

An earlier form of this paper was delivered at the American Historical Association Regional Conference on the Teaching of History, Purdue University, West Lafayette, Indiana, December 1, 1978. 
exposed to alternatives--at least many students have not. The fallacy here is that defenders of this approach equate synthesis with coverage.

b. Modular-Conceptual History tries to get away from the weaknesses of descriptive history by suggesting that history is not purely objective; showing that history is a series of problems; and revealing that history can be more enjoyable if one tries to understand certain "processes" (e.g. the nature of revolution). But modular-conceptual runs into other problems. Teaching history as a grand design can indeed pose several possibilities of synthesizing large chunks of material; but that design may be more Hegelian than human. Pre-selection of data by the instructor (or the editor of the reader being used in the course) may lead the student away from actual process because of the editor's or teacher's biases that interpose a conscious or unconscious manipulation of evidence, data, or documents toward a predetermined conclusion. In such a situation, the student is not much better off than under descriptive history because here the synthesis is contrived, indeed "synthetic."

c. Analytical-Problem History attempts to satisfy the weaknesses of the prior approaches. While using a chronological approach, it does not attempt to cover the gamut of the subject, but rather concentrates on a few selected problems. In this manner, the student gains insight into analytical history, by examining the primary documents and drawing interpretations, and by critically analyzing secondary sources on the subject. A major weakness of this approach is the need to teach the process and to persuade students to think about history in this (for many) new way. And, if it should be a constant method used by more than one instructor, the student is subjected to a repetition of process, which could make for a course as boring as "namesdates-places."

In considering these three models, we hoped to structure the 101 course in such a way so as to fulfill the needs not only of students taking only one history course but also for potential majors, basically by making the analytical-problematic approach more explicit and by developing and teaching a sequential and cumulative set of skills.

During our labors with designing and piloting the course, the department was confronted by the implications of its second promise for 10l: finding a place for history in the general education curriculum. Like many schools, Bowling Green recently decided to revise its freshman and sophomore curriculum. General education previously had meant the fulfillment of course requirements in five very broadly defined areas (e.g. the "fine and practical arts"). As these areas evolved over the years, however, the inclusion of courses within a particular area tended to reflect political as much as academic realities. Moreover, the inroads of increasingly specialized programs and the emergence of professional colleges further weakened general education. And finally, the popularity of "vocationalism" among students (and their advisers) predisposed them to view their college careers increasingly as an entry to the job market, and they chose their courses accordingly. The result was a serious erosion of a rational and coherent curriculum.

Yet curriculum revision, for all who desired it, has not been easy to accomplish. In 1978, the academic council of Bowling Green decided on a list of ten "outcomes goals" which would form the basis of the general education curriculum. At an entry level, students would be expected to "develop and demonstrate essential skills in:"

1. Problem solving and critical thinking;

2. Reading and writing; 
3. Computation and mathematics;

4. Listening and speaking;

5. Decision-making and values conflict resolution.

A second group of outcomes called for students to "achieve a functional understanding of:"

6. Literature, the film arts, and other humanities;

7. The natural sciences and technology;

8. The social and behavioral sciences;

9. Cultures other than one's own;

10. Personal development.

These outcomes statements reflect the influence of other schools, such as Alverno College which has shifted not only to an outcomes-oriented curriculum, but also to competency testing as well. But Bowling Green stopped short of competency testing because of protests that it would lead to a whole new testing bureaucracy and an inevitable increase of administrators. Whether or not this argument was valid, it did persuade implementors to switch to the consideration of a core-curriculum. As these discussions got under way, the question arose: what was history's role in the curricular changes? Would the department simply attempt to seek certification for courses within the second set of outcomes (particularly nos. 8 and 9), or could the department also make a contribution to that first set of outcomes, which stressed acquisition of basic skills and which also held the promise of reaching some new groups of students? We believed that the 101 course could apply to the first two outcomes, and in tailoring the course to those outcomes we discovered some things that we believe are important to those who have similar concerns.

We find that we are in a kind of microcosm; that is, the problems we encountered within the department in building the course are quite similar to the problems the university as a whole faces with implementing the general education outcomes. The content-versus-method dichotomy which enlivened our curriculum committee deliberations is now campus-wide. Those advocating change are seen as critics of the existing system, something which some defenders take personally. Perhaps the only comfort that can be drawn from this is that historians are willing to come to grips with general-education-type introductory history courses. This may put them at an advantage in addressing the larger issues of general education reform when and if they arise. And we think they will. We are back in that cycle.

Many defenders who would put history into a general education curriculum are finding a more difficult time defending the uniqueness of history. Granted, Harvard's curriculum reform specifically included history, but we do not see that occurring in very many other places. On what grounds do we defend history's inclusion? One answer seems to be that historians understand the relation between content and method. Our problem has been that we have seldom, at least to our introductory students, made that relationship clear. Students tend to regard conventional history texts as a combination of Holy Writ and the Chicago telephone directory, possessing the authority of one, the boredom of the other, and the relevance of neither. Thus, whatever attempts are made to incorporate ideas of historical thinking or critical analysis become lost in the welter of data. Students may glimpse that history involves many acts of analysis by the historian, but they get no systematic practice at finding out what those acts are. History's contribution to general education lies not so much in its breadth of content, which has been its traditional claim, but in the breadth of skills that it can offer. For one thing, critical analysis in history does not require the 
memorization of a specialized (and often arcane) vocabulary as do many other disciplines. We still struggle with everyday language as our tool. We also have literally the world of experience from which to choose our materials on which we would have our students practice. If they cannot get into "What happened on Lexington Green?" they can get into "What happened in Northern Ireland?" or "What happened on Blanket Hill at Kent State?" To that extent we have a freedom that is almost limitless. Another unique quality of introductory history courses that emphasize general education components is their emphasis on teaching such skills as reading, writing, and critical thinking. We would suggest that history's traditional image as a "synthesizer"--this time of skills--can be refurbished and enhanced.

HISTORICAL PROCESSES, GENERAL EDUCATION, AND THE SPECIFICS OF THE 101 COURSE

In designing the syllabus and reading list for The Study of History, we proceeded upon several findings and assumptions about our potential students: they liked individual courses and instructors in the department but still were repelled by the utility of history per se; they were increasingly vocational-minded: the 80 per cent decrease in the number of majors over the previous decade symbolized the dramatic decreases throughout the liberal arts disciplines; and they might take the course if convinced that the "tools" of history would aid them in their career choices (this assumption admittedly was, and is, a long shot). Thus, the task was to make explicit the skills we wanted to teach:

1. Ascertain facts;

2. Distinguish between facts and judgments;

3. Distinguish between an opinion (no evidence) and an inference (judgment based on evidence);

4. Extract the major ideas from documents as well as the author's hypothesis;

5. Recognize an author's frame of reference and mind-set (By frame of reference we meant that people's perceptions of past data or experience are dependent on their range of experience in the present. And by mind-set we meant the cultural perceptions surrounding the production of the document or work being studied. Thus we hoped to teach awareness of two levels of perception: the students' and the authors they were studying.);

6. Develop and defend a hypothesis;

7. Develop an attitude of skepticism about data;

8. Ask penetrating questions about what one is reading;

9. Show proficiency in

a. writing book reviews that transcend mere summary (to evaluate the hypothesis, mind-set, and use of evidence by an author);

b. doing family history research that required identification and evaluation of primary source materials, and which required making distinctions between facts and judgments.

Operating under the time restraints of a ten-week quarter, we developed three exercises through which we hoped to achieve our goals.

Exercise No. 1. Develop sequential and cumulative skills in the student in identifying and categorizing evidence, identifying frame of reference, and examining internal evidence.

In this exercise we wanted students to be particularly aware of the differences between facts, opinions, and reasoned conclusions. Accordingly, we assigned relevant portions of David Sanderlin's Writing the History Paper 
and John Good's Shaping of Western Society. We chose these materials because they defined and demonstrated the various aspects of historical inquiry--fact, hypothesis, and inference (Sanderlin's use of the "riding your own hobby horse" metaphor was useful in describing frame of reference).

We also did a simple exercise, the "Coin Game," in which students were to imagine themselves as members of a non-earth culture who recently acquired some artifacts on an expedition to a planet that had been destroyed in a nuclear holocaust. They were to deduce the nature of the civilization that had produced the artifacts--which in reality was the loose change in their pocket but which now they had to examine through different eyes, without any traditional frame of reference. Since students chose different "facts" from the artifacts--were they even coins?--they soon clashed over interpretations of what the coins meant and sometimes allowed their earth-bound assumptions to affect their judgments, a "violation" of one of the rules of the game.

After introducing the process of historical skepticistn and the importance of recognizing frame of reference, we turned to an assignment which required students to apply the skills which they had learned--develop and defend a hypothesis with regards to what happened on Lexington Green (To accomplish this we employed Peter Bennett's What Happened on Lexington Green?, a collection of primary sources and secondary interpretations.) There were three processes students applied in this exercise. First, they had to examine, identify, and categorize evidence. Second, they had to ascertain how frames of reference influenced the recollections of each of the primary sources. Third, they had to develop and defend a hypothesis about what happened at Lexington Green. Upon completion of the exercise, we hoped the students had recognized the dual dilemma that an historian faces: first, the historian must depend upon accounts which are biased, because each account views a situation differently, a product of frame of reference; and, second, no two people interpret data the same way. One's own view of the world is clouded by one's own perceptions.

\section{Exercise No. 2. Give the student a taste of some research.}

Having introduced the students to some of the processes of historical thinking we next turned to a project which would require students to use the inquiry skills which they had learned and, at the same time, would demonstrate a direct correlation between the student and history. The family history was to be a step in bridging the gap between history and the student's life. As reported in a number of studies that have utilized family histories, the research would begin with the particular; it would demonstrate the need to understand certain inquiry skills--particularly frame of reference; and there would be controlled research--controlled in the sense that the students would have one month to do it and that they would research their histories only as far back as their grandparents. For this purpose, Watts and Davis, Generations: Your Family in American History was very helpful, particularly the short autobiographical excerpts demonstrating mind-sets and the impact of social, economic, and political forces. Equally helpful were the family history research aids, directions, charts, and graphs at the back of the book.

We spent the first week of this period reinforcing the distinction between fact and inference, and the role that frame of reference played in determining one's approach to the topic. The second week concentrated on research techniques and the role of mind-sets in determining the "value-orientation" of a culture/society. At the end of the second week, we collected a 500-750 word autobiography which dealt with those people, places, and events which had most influenced the lives of the students. While many of the papers dealt 
with the personal and the immediate, we hoped that the assignment had given the students a chance to apply some of the methods they had learned. (At the same time we hoped that it gave them something to shoot at: What happened in their family's past which caused them to be the type of person they were?)

The next week and a half were dedicated to helping the students place their families in historical context, by studying some of the major movements, and their corresponding value systems, which had influenced America's development (immigration, the Depression, World War II). We tailored these topics to correspond with Watts' and Davis' chapters.

At the end of the fourth week, the family histories were collected. The majority of the papers were well-researched and well-thought-out. The students had grappled with the effects of mind-set and frame of reference on their ancestors' oral presentations. More importantly, they had come to understand the influence of history on their family's development. Hopefully, by having the students research and write family histories, we generated some enthusiasm for history by getting the student to see the relationship between his or her life and the "so-called" larger impersonal forces of history--and in this way they recognized that history is relevant.

Exercise No. 3. Develop better analytical reading skills and critical writing skills.

This assignment had two goals. The first was to read a book, identifying the author's hypothesis, argumentation, and frame of reference. The second goal was to teach students how to analyze the book critically, going beyond a mere summary. The problem here was to show students how they could use their admittedly shallow knowledge and judgments to make valid comments. David Potter's People of Plenty. was useful for these goals because Potter's main and subsidiary hypotheses were readily identifiable and the students could use the conclusions which they had made in their family histories as evidence by which to evaluate Potter's argument. Two subsidiary rationales were also evident: People of Plenty introduced the student to another historical approach--while Generations was chronological, Potter was thematic; and it could be used as another span in the bridging process between the individual and history.

In assigning chapters in the book, however, we omitted the first portion, which is a detailed discussion by Potter of his approach to the topic and of the relation of history to the social sciences. This section of Potter also provided insight into mind-set, frame of reference, and methodology. Given the purpose of the course, it may seem odd that we cut out these chapters, and, in retrospect, we regret that decision, although we believed at the time that they were too difficult and time-consuming for freshmen. Instead we stressed the need to examine the author's evidence, logic, and assumptions. In our attempt to achieve this goal we became so involved in the content of the book that we overlooked the processes. They (and we) fell into the old trap of viewing history as simply information to be digested. We also found that we had to spend a great deal of time providing background information (1.e. an abridged survey of American history), in order for the students to understand not only Potter's interpretation, but also to understand that it was only an interpretation. Consequently, the book analyses were disappointing because most of them simply summarized the material. A combination of our failure to examine Potter's method and the naivete of undergraduates when it comes to interpretive history are but two reasons explaining this poor showing.

Obviously we had compressed too much into too short a time period. Writing a book analysis and trying to place one's self (or family) into "the 
mainstream of history" are two very different skills, and we should have more consciously separated them. Since the students had just finished original research into family history, it would have been logical to require them to do an anlysis of a monograph on family history, such as Alex Haley's Roots. If, then, we had wanted them to become aware of certain historical forces, we could have concentrated on one or two of Potter's ideas--particularly his chapters that show the influence of mobility and status in shaping the American character.

Nevertheless, our students did become aware of some historical forces. In one of the most successful parts of the course, preceding our study of Potter, we played the "Necklace Game," an open-ended, ostensibly nondirectional simulation that revealed to students something about their behavior, particularly their desire to "win" (mobility) and their desire to "stay on top" (status). Each player was given eight poker chips of different colors that denoted different point values. The players were told to trade the chips to increase their total number of points. They had to be careful, however, not to have fewer than eight chips, or too many chips of any one color because in either case they would, in effect, lose points. Each player also wore a "necklace" that was a square, triangular, or circular piece of cardboard, but they were not told what the shape meant. After each trading session--there were three, each lasting about five minutes--the points were tallied, and the highest one-third of the players were designated "squares," the next one-third "circles," and the bottom third "triangles." If they were not wearing the necklace that corresponded to their status, they had to obtain one from another player. The distribution of these new "classes" were accompanied by a great deal of fanfare from the instructors, which was quickly emulated by the students.

The squares, triangles, and circles then caucused to prepare for the next round of trading. In these caucuses, each class was given four chips (each worth 100 points) and told that they had to distribute those chips among themselves--there were about ten to twelve in each class--and to reach that decision unanimously. If, however, there were one or two dissenters, they could be ejected by the rest of the group. Meanwhile, the squares were secretly informed that they could promulgate any rule they wished to govern the next trading round. In case they missed the point, the instructors (who were doubling as agents provocateur) suggested that unless the squares were careful, some of them might lose their privileged position; thus they might want to pass a law that protected their status.

After two rounds of trading, the squares were "exploiting" the circles and triangles thoroughly; the lowly triangles were hiding their chips and discussing how to "revolt" against the squares, and the circles (middle class?) were totally confused. Should they join the triangles in revolution, or should they seek acceptance from the squares?

At this point of social disaggregation, the instructors stopped the game and asked the students to analyze their own feelings and each other's behavior. How did each perceive his or her group? The other groups? Why did the squares feel it necessary to climb on top of the instructor's desk to announce their rules? Why did some of the triangles want to drop out of the game? Why were some of the individuals so intent on trading that they practically man-handled others? Why were others becoming angry? During the evaluation, some of the students expressed surprise at their own behavior ("I can't imagine that I did those things!"), at which point the instructors asked them to analyze the climate that the game had produced. Then, we asked them to what extent they believed the game to be representative of reality: How do Americans measure success, mobility, and status? 
What types of behavior are engendered by the way in which society defines those concepts?

Not only did the students respond extremely well to the Necklace Game, but they also got to know each other much better. The game may have been devoted to cut-throat competition, but it promoted a degree of cohesiveness among the s.tudents that was soon evident in the way most of them interacted. It also encouraged a few others to participate more in class discussion, and, for several, the game provided a focus for and a reason to become more involved in the course. The students had difficulty, however, applying what they had learned about mobility and status from the game to Potter's book.

In subsequent offerings a different tack to Potter was taken. The opening two chapters of Potter were restored and more time was spent examining the relationship between history, anthropology, and social psychology. (That examination was further reinforced this year in the section on Lexington Green wherein students were asked to compare economic, literary, and psychological approaches to the battle.) And more time was devoted to the book. This allowed more opportunity to look at history as a process and to allow students to examine the ramifications of the thesis.

\section{EVALUATION}

Did we succeed in teaching historical processes? The initial conclusion which could be drawn from the information given is that this course failed in instilling historical skepticism and in destroying the myth of historical objectivity. A closer look, however, would prove this initial inference false. History 101 was designed for the freshman student who was the product of the high school history course which portrayed history as objective. Entering college, this student had that belief shattered, and it was only natural for the ingrained, the orthodox, to attempt to undermine the heresy. In this case, in a course of process, the student was starved for content, and when he finally acquired it, he latched onto it, fearing that if he did not hold tight, he might lose it.

As instructors, we also were partly to blame. In our attempt to structure the course so that it would proceed from the particular to the general, we inadvertently chose related sources. The question therefore arises: were we subconsciously also interested in conveying content as well as process? Given the student's mind-set of history, and our own mistake, it was only natural for the students to have desired content as highly as they did. Solace can be taken in the fact that the students recognized the primary goal of the course to be the process, and that they, at least in their estimation, had acquired this goal. A few students even recognized the sequential evolution of the course (i.e. that the skills they had learned were sequential and cumulative). This strongly suggests that they had internalized to some extent some of the course objectives, and that it was possible to combine history and general education.

What of the students' overall attitude toward history? At the risk of over-simplifying the responses, it appears that they were more reserved in their opinions about history per se. Most of them recognized for the first time that history was more than just "names-dates-places," that it involved analysis and judgment, and that certain skills were necessary, not only for historical analysis and judgments, but also for application elsewhere.

Would they take another history course--which after all was a prime objective of 101? Nearly half the respondents said that 101 would play no 
role in deciding whether or not they would go on; and an equal number indicated that 101 influenced them somewhat favorably toward going on. of the remaining three, one said that he/she was influenced a great deal to go on; one said the opposite; and the last one did not know. Although the results were not as favorable as hoped for, it should be remembered that nearly all the respondents were first quarter freshmen, displaying the usual array of uncertainty and bewilderment of majors, minors, course sequence, and career options, and that several of the students came into the course expecting a standard survey. Evidently the victims of bad (or no) advising, these students decided to stay on, even though the course's intents and methods were made clear the first days of class. It was either too much of a hassle to rearrange class schedules to accommodate a survey course, or else they thought that they would stay on to see what it was like. In either case their expectations were frustrated or else illformed. As for enrollments in History 101: at Bowling Green, as in most schools, it takes time and "the grapevine" for a course to either blossom or to wither. The first time the course was offered, it attracted a total of 55 students (both sections). Enrollments in subsequent quarters of History 101 have been at least double that of the initial offering.

As of this writing, no university-wide decision has been reached about general education revision or of history's role in it. The general education component of 101--i.e. skills development--is, however, being taken seriously in the revision of other basic history courses, particularly the world civilization courses.

In summary, History 101 was designed to fulfill four objectives: to relieve the burden and potential repetitiveness of subsequent courses devoted to historical analysis; to show that "historical thinking" was applicable in courses other than history; to make room for history in a general education curriculum; and to stimulate enrollments in other history courses. The last goal at this writing does not appear to have been met; it is too early to tell whether the students see the applicability of historical thinking elsewhere, partly because so much time was spent in trying to change their concept of history. One is tempted to speculate that there are are more ingrained prejudices--perhaps positive, but more often negative (according to the authors' values)-about history than about any other discipline that students bring to college. And as any learning specialist knows, "paradigm shifts"--getting students to change their perceptions and approaches to a discipline--are among the most difficult behavioral goals to attain. 